RESEÑA BIBLIOGRAFICA

\title{
Impacto ambiental temprano en la Araucanía deducido de crónicas españolas y estudios historiográficos
}

\author{
Early environmental impact in the Araucania territory inferred from Spanish chronicles \\ and historiographical studies \\ FERNANDO TORREJON ${ }^{1}$, MARCO CISTERNAS ${ }^{2}$ \\ ${ }^{1}$ Centro Eula-Chile, Universidad de Concepción, Casilla 160, Concepción, Chile. \\ ${ }^{2}$ Facultad de Agronomía, Universidad Católica de Valparaíso, Casilla 4-D, Quillota, Chile.
}

\section{SUMMARY}

Chilean historiography states Araucanian territory kept its pristine conditions until the republican period beginning. However, the presence of border military enclaves would have produced an early environmental disturbance in the Araucania. To validate this hypothesis, a study of the Spanish chronicles, old documents and historiographical studies was done. Results indicate there was significant environmental disturbance on the Araucanian ecological system, as a result of the intercultural contact during the Arauco war and the Spanish-Creole settlement. Native species extinction, exotic species introduction, Mapuche crops substitution, natural resources mistreatment, land use changes, Mapuche culture modification, and Araucanian mortality and migration rising are among the environmental effects occurred under the area influenced by the forts.

Key words: ecological landscape, early environmental disturbance, Spanish settlement, Araucania, Chile.

\section{RESUMEN}

La historiografía chilena sostiene que el territorio araucano mantuvo condiciones prístinas hasta los inicios del período republicano. Sin embargo, la presencia de enclaves militares españoles fronterizos habría generado temprana intervención ambiental en la Araucanía. Para validar esta hipótesis, se realizó un análisis de las crónicas españolas, documentación de la época y de estudios historiográficos. Los resultados indican que existió significativa perturbación ambiental sobre el sistema ecológico araucano producto del contacto intercultural durante la guerra de Arauco y el proceso de poblamiento hispano-criollo. Entre los efectos ambientales, generados en el área influenciada por los fuertes, se reconocen extinciones de especies endémicas, introducción de especies exóticas, sustitución de cultivos mapuches, explotación predatoria de los recursos naturales, cambios en el uso del suelo, modificación de la cultura mapuche y aumento de la mortalidad y migración araucana.

Palabras claves: ecología del paisaje, intervención ambiental temprana, colonización española, Araucanía, Chile.

\section{INTRODUCCION}

Tradicionalmente se ha considerado que el territorio indígena al sur del río Biobío (figura 1) mantuvo características ambientales relativamente prístinas durante la mayor parte del período de Conquista y Colonia española (1542-1810), a di- ferencia de lo acontecido en los territorios situados inmediatamente al norte (Cunill 1970).

Sin embargo, la Araucanía, a pesar de su independencia política conservada hasta mediados del s. XIX, habría recibido, desde los inicios de la Conquista, una influencia directa y constante de la cultura hispana. Los tempranos y antagónicos 


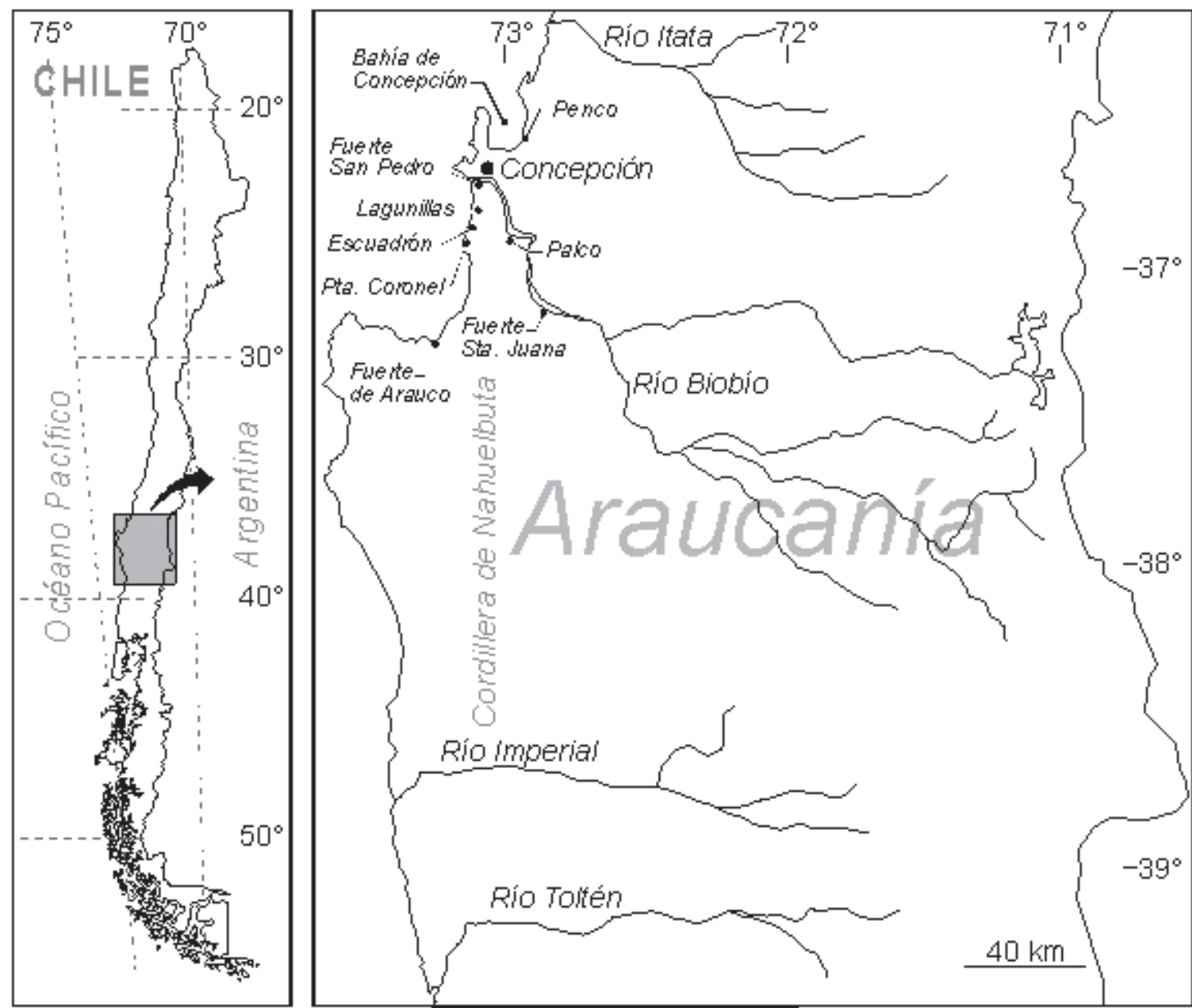

Figura 1. Mapa de localización (s. XVI-XVII).

Location map ( $16^{\text {th }}-17^{\text {th }}$ centuries).

contactos entre una cultura capitalista y una sociedad tribal neolítica (Villalobos 1995) habrían generado cambios decisivos en la cultura mapuche, desencadenando un proceso aculturativo (sensu Zapater 1985), cuyas consecuencias se reflejarían en la alteración física del hábitat araucano.

En este sentido, los asentamientos militares españoles jugaron un importante rol en la progresiva modificación de las características ambientales araucanas durante la guerra de Arauco (1550-1662) y el poblamiento colonizador de los siglos XVII y XVIII. Paralelamente a las acciones bélicas, los enclaves militares promovieron el desarrollo de núcleos periféricos de colonos hispano-criollos (Villalobos 1995), coexistiendo con pequeñas agrupaciones indígenas (Góngora 1966, Cunill 1971). A medida que el poblamiento se consolidaba, la presión tanto indígena como hipano-criolla sobre los sistemas naturales fue aumentando proporcionalmente.

Ambos procesos, la guerra y el poblamiento colonial, han sido estudiados con detalle por la historiografía tradicional (Barros Arana 1884-1904, Encina 1947); sin embargo, sus implicancias histórico-ambientales nunca han sido tratadas. Sobre la base de lo anterior, el presente trabajo pretende reconocer, mediante documentación de época, el rol de estos procesos históricos en la degradación ambiental del sistema ecológico araucano. Los resultados servirán de base para un mejor entendimiento de las problemáticas ambientales que hoy afectan a la Araucanía, considerando que el paisaje actual es producto de la intervención humana durante 500 años y no sólo del último siglo. 


\section{MATERIAL Y METODOS}

Area de estudio. Se consideró como área de estudio el sector central y septentrional de la Araucanía (figura 1). Araucanía fue la denominación dada por los españoles al histórico territorio mapuche cuyos límites aproximados eran los ríos Itata, por el norte, y Toltén, por el sur, limitando al este con la Cordillera de los Andes y al oeste con el Océano Pacífico ( $36^{\circ} 30^{\prime}-39^{\circ} 00^{\prime} \mathrm{S}$; $71^{\circ} 30^{\prime}-73^{\circ} 15^{\prime}$ W). En la actualidad dicho territorio, con más de $50.000 \mathrm{~km}^{2}$, abarca gran parte de la VIII Región del Biobío y IX Región de la Araucanía, Centrosur de Chile (Guevara 1925, Krumm 1971, 1972).

Análisis bibliográfico. Se recopiló, seleccionó y analizó el material bibliográfico disponible. Se examinaron principalmente tres categorías documentales: i) estudios contemporáneos, ii) fuentes históricas impresas y iii) documentación manuscrita (Biblioteca Nacional, Archivo Nacional de Chile y otros). Se privilegiaron los antecedentes históricos directos (crónicas, documentación epistolar e informes administrativos) de los funcionarios coloniales. Relevante fue la utilización de las descripciones e informes de naturalistas y funcionarios militares que visitaron la zona fronteriza de la Araucanía a fines del s. XVIII e inicios del s. XIX.

Análisis cartográfico. Complementando el trabajo anterior, se estudió la cartografía de los siglos XVII, XVIII, XIX y XX. La información obtenida fue comparada con la cartografía actual (Cartas IGM 1988, escala. 1:50.000) y las primeras fotografías aéreas de la zona (vuelo TRIMETROGON 1943, escala 1:40.000 y vuelo HYCON 1955, escala 1:70.000).

\section{RESULTADOS}

Cosmovisión de españoles e indígenas respecto al medio natural. La concepción cristiana antropocéntrica del universo fue predominante en la mentalidad europea medieval y renacentista. Esta visión percibía que la naturaleza estaba al servicio del hombre por designio divino; es decir, hombre y naturaleza aparecen disociados (sensu Meffe y Carroll 1994). Tal idea, culturalmente internalizada en los conquistadores españoles, se enfrentó con la cosmovisión indígena, donde las prácticas mágico-religiosas de los mapuches, de carácter animista, otorgaban condición de prodigio a distintos fenómenos de la naturaleza, incluyéndolos en el ámbito de lo sacro (Villalobos 1983), por lo que naturaleza y hombre formaban una sola unidad.

Condiciones ambientales prehispánicas de la Araucanía. De acuerdo a Villalobos (1983), la presencia aborigen precolombina significó algún nivel de intervención en el hábitat puntualmente ocupado. Sin embargo, la mayor parte de la Araucanía habría mantenido condiciones prístinas (Bengoa 1991).

Sólo ocho años después de la llegada de los españoles a la Araucanía (fundación de Concepción en 1550), el cronista Jerónimo de Vivar describe, por primera vez, el sistema natural araucano. Vivar, testigo privilegiado e intuitivamente científico, observó que al sur del río Itata existía "otro temple, que hay ynvierno y verano, y llueve más, y los vientos más furiosos. No es de rregadio, y los bastimentos se crian con el agua que rreçiben de ynvierno. Y d' este valle de Ytata no hay algarrovas ni espinillos, de los que dicho tengo de Mapocho [...]. Junto a la çiudad de la Conçiçion pasa otra cordillera pequeña. Y va de la mar esta cordillera media legua y una legua y en partes menos, y es muy montuosa de grandes árboles y [c- arraianes] y lavreles, y otros arboles grandes que llevan vna fruta a manera de nuezes. Y antes que despidan la cascara y desque está madura, esta fruta es amarilla, y d' ella se haze miel y vn brevaje muy bueno [...]. Y este arbol solamente le ay en tres leguas en torno de la Conçeçion, y en otra parte no la ay ${ }^{1}$. Ay muchas cañas maçiças. Ay en esta tierra vn arbol muy alto a manera de pino, salvo que no tiene rrama, syno solamente vna copa en lo alto. Llevan estas rramas o copa vnas piñas que casy se parecen a las del pino en el llevar de los piñones, [...] y sacan unos piñones d' ellas mayores que almendras. Éstos pasan los yndios y los comen cozidos [...]. D' estos arboles ay en

\footnotetext{
Esta descripción concuerda con las características del Queule (Gomortega keule), árbol endémico y un elemento relicto de la flora nativa de Chile, actualmente en peligro de extinción (González et al. 1991, Rodríguez et al.1995, San Martín y Donoso 1997).
} 
algunas partes. Ay gran cantidad pasado del rrio de Bibio para adelante ${ }^{2}$.

Ay otro arbol no muy alto, lleva vn fruto como avellanas, salvo que no tiene tan dura la caxcara syno blanda, y no tiene capillo. Lleva vna rrama tres y quatro y más cantidad junta. Son como avellanas, y quando estan maduras estan coloradas y saben a vellotas ${ }^{3}$.

Ay en algunas partes otro arbol que dizen 'molle'. Y ay otros arboles muy buenos de que hazen madera para las casas. De la frutilla que dixe en la ciudad de Santiago, aparrada por el suelo ay muy gran cantidad, de la cual hazen un brebaje los yndios para beber [...]. Y los naturales tienen mays y frisoles y papas y vna yerva a manera de avena, qu' es buen mantinimiento para ellos [...]. $\mathrm{Y}$ ay muchas yerbas pareçientes a las de nuestra España."[1].

De acuerdo con autores contemporáneos, al inicio de la Conquista la población mapuche, que ocupaba los diferentes hábitat existentes entre los ríos Itata y Toltén, se estimaba en 500.000 personas (Villlabos 1983, Bengoa 1991). El área de mayor concentración demográfica se localizaba en ambas vertientes de la cordillera de Nahuelbuta y la llanura costera, desde el río Biobío al Imperial (figura 1), tratándose de un poblamiento sedentario de tipo disperso (Bengoa 1991). Según Villalobos (1983), la llanura costera, que se localiza entre Concepción y Arauco, habría sostenido una población de 40.000 indígenas. Algunos sitios arqueológicos del área (conchales de Lagunillas, La Posada y Escuadrón) permiten remontar el origen de este poblamiento al período precerámico (Stehberg 1980).

Esta concentración poblacional se explicaría por la fertilidad del territorio, capaz de generar los recursos necesarios para la manutención de sus habitantes. Los ríos, lagos y lagunas eran fuente de peces comestibles, mientras que en los bosques de Nahuelbuta crecían árboles cuyos frutos (con

2 El árbol referido concuerda con las características taxonómicas de la araucaria (Araucaria araucana), especie endémica de las regiones del Biobío y Araucanía, cuyo estado de conservación es vulnerable. Actualmente no se observan especímenes en los alrededores de Concepción (González et al. 1991, Rodríguez et al. 1995).

3 La especie concuerda con las características del avellano (Gevuina avellana), árbol endémico de Chile, que se encuentra desde la provincia de Curicó hasta las islas Guaytecas (González et al. 1991, Rodríguez et al. 1995). un alto valor nutritivo) formaban parte de la dieta indígena. No menos importante era la abundancia de presas de caza, destacando entre ellas el guanaco (Lama guanicoe), el huemul (Hippocamelus bissulcus), el pudú (Pudu puda) y otras menores (Bengoa 1991).

Del mismo modo, los recursos marinos fueron fundamentales en la alimentación y economía indígena, principalmente entre los mapuches costeros o lavquenches ${ }^{4}$. El mar proporcionaba gran cantidad y variedad de peces, mariscos y algas, prevaleciendo entre estas últimas el cochayuyo (Durvillea antarctica) y luche (Ulva lactuca). Los excedentes de estos productos, secos o deshidratados, eran intercambiados con los araucanos del interior, generándose un activo trueque (Guevara 1925, Masuda, 1998).

El conquistador Pedro de Valdivia también reconoció la abundancia del litoral araucano. El 15 de octubre de 1550 describía a Carlos V las características de la bahía de Concepción: "de la mejor pesquería del mundo, de mucha sardina, céfalos, tuninas, merluzas, lampreas, lenguados y otros mil generos de pescados"[2]. En el mismo sentido, mientras se construía la recién fundada ciudad de Concepción del Nuevo Extremo, Vivar escribió: "Y muchas vezes y avn muchos dias, no comiamos syno mejillones y marisco sacado de la mar, y cogollos chicos y rraizes de achupallas, que son a mitaçion [sic] de palmitos"[3].

La presencia de recursos alimenticios, sumada a la disponibilidad de tierras aptas para el laboreo agrícola, explicaría la sustentabilidad del sistema económico de la sociedad mapuche. Villalobos (1983), Bengoa (1991) y Chonchol (1994) coinciden en señalar que la economía araucana se basaba fundamentalmente en la recolección, caza y pesca, otorgándoles a la agricultura y ganadería un carácter incipiente y de subsistencia. Sin embargo, otros autores sostienen que la agricultura y, en menor escala, la ganadería ${ }^{5}$ eran las principales

4 Denominación geográfica recibida por los habitantes del lavquenmapu o región de la costa. Esta subdivisión del territorio mapuche comprendía la vertiente occidental de la cordillera de Nahuelbuta y la llanura litoral, entre los ríos Biobío y Toltén (Guevara 1925, Krumm 1971-1972).

5 Es probable que la llama (Lama lama) haya sido el único animal criado con fines ganaderos por los mapuches, quienes la denominaron "hueque o chilihueque". Los españoles la llamaron "carnero u oveja de la tierra" (Latcham 1922). 
actividades de la economía araucana, ambas complementadas por la recolección, caza y pesca (Amberga 1917, Latcham 1936, Bullock 1958).

Esta última posición es, en alguna medida, corroborada por la documentación de la época. Pedro de Valdivia, después de recorrer parte de la Araucanía, escribía el 25 de septiembre de 1551 que la tierra era "próspera de ganados como los del Perú, con una lana que le arrastra por el suelo; abundosa de todos los mantenimientos que siembran los indios para su sustentación, así como maíz, papas, quinua, mare, ají y frisoles"[4]. Lo anterior se refuerza con la crónica de Vivar: "los naturales tienen mays y frisoles y papas y vna yerva a manera de avena, qu'es buen mantinimiento para ellos. Son muy grandes labradores y cultivan muy bien la tierra"[1].

Como se puede deducir, el sistema ecológico araucano, abundante en recursos, era capaz de sostener a una importante población indígena que, probablemente, debido a su estadio de desarrollo, no entró en conflicto con el ambiente natural circundante. Esto permitió que la Araucanía conservara grandes áreas prístinas ya que las actividades productivas mapuches no fueron intensivas. Por el contrario, existía una armonía y equilibrio entre espacio, recursos naturales, habitantes y técnicas (Pacheco 1991). En resumen, la sociedad mapuche precolombina contaba con una estructura armónica tanto en sus relaciones con la naturaleza como en sus relaciones culturales (Bengoa 1991).

Efectos ambientales de la guerra de Arauco. El impulso conquistador español obedeció mayoritariamente a la atracción ejercida por los recursos naturales existentes en la Araucanía (Pacheco 1991). De acuerdo al criterio económico mercantil de los conquistadores, se pretendía dominar y ocupar extensas áreas geográficas para así explotar sistemáticamente el entorno; esto, mediante labores extractivas como la minería aurífera, tala maderera, y a través del desarrollo de actividades agropecuarias intensivas.

Para realizar la explotación económica de la Araucanía era necesario someter a los indígenas, considerados como mano de obra para los lavaderos y el trabajo agrícola (Pacheco 1991). Sin embargo, este plan fue obstruido por la resistencia araucana a perder su territorio e independencia. De este modo, con el avance español al sur del Itata, se inició la guerra de Arauco que, con inten- sidad variable, enfrentaría a mapuches e hispanos hasta la segunda mitad del s. XVII (Villalobos 1995), aun cuando las hostilidades nunca cesaron del todo.

El despojo y servidumbre forzada a que fueron sometidos los indígenas se evidenciaron desde el primer contacto. El 15 de octubre de 1550 Valdivia afirmaba que una vez fortificado el sitio de Concepción, "hice recoger la comida que había en la comarca e meterla en nuestro fuerte, e comencé a correr la tierra y a conquistarla [...] en cuatro meses traje de paz toda la tierra, que ha de servir a la ciudad que aquí he poblado." [5].

Además de las lógicas secuelas que acompañan a todo proceso bélico, la guerra de Arauco tuvo efectos sobre el paisaje ecológico araucano, generando notorias alteraciones ambientales. Las continuas depredaciones españolas sobre el ganado y recursos agrícolas indígenas contribuyeron a las tempranas extinciones locales de animales nativos de crianza, como la del chilihueque 6 . "Quando entramos en esta tierra los españoles avia ganado [chilihueques], avnque no mucho, y con las guerras se an acabado, por lo qual no ay agora ninguno, [a- sino] qual o qual, porque donde entran españoles, espeçialmente en conquistas son como las langostas en los panes"[6]. Paralelamente, fue disminuyendo la diversidad de especies vegetales sembradas en las chacras indígenas, que asumían la forma de policultivos (Cunill 1998). Se fueron restringiendo cultivos nativos como la quinoa (Chenopodium quinoa) y el madi (Madia sativa) a sectores más apartados de la Araucanía, desaparecieron algunas variedades de granos como el mango (Bromus mango) y la teca (Latcham 1936, Bullock 1958).

De este modo, los araucanos sustituyeron especies, representativas de su tradicional actividad económica, por vegetales y animales introducidos. Tanto los nuevos cereales como el ganado exótico, principalmente caballares, vacunos, ovinos y caprinos, se aclimataron y reprodujeron rápidamente debido a las favorables características ambientales del nuevo hábitat. Así lo describía Vivar:

\footnotetext{
6 El chilihueque u oveja de la tierra siguió existiendo al interior de la Araucanía, en lugares alejados de los españoles. Sin embargo, a fines del s. XVII los mapuches reemplazaron totalmente a la llama por el ganado exótico, situación que definitivamente provocaría su desaparición de la Araucanía y sur de Chile (Bengoa 1991).
} 
"Dase mucho trigo y çebada [...]. Dase toda la ortaliza de nuestra España y legumbres. Y anse puesto sarmientos y danse muy bien, y higueras. Y se daran todas las demas plantas de nuestra España muy bien, porque el temple es muy bueno"[1]. Refiriéndose a la propagación del ganado introducido durante la segunda mitad del s. XVI, el cronista Mariño de Lobera escribió: "Todas estas tierras de Arauco y Tucapel, y las demás circunvecinas son tan excelentes en todo [...], pues todo está lleno de mantenimientos de los hombres y cuando menos de pastos para los ganados, donde hai ovejas sin número, y otras muchas reses, fuera del ganado vacuno que despues de la entrada de los españoles, es tan sin tasa, que se lo lleva de balde el que lo quiere"[7].

A pesar del alzamiento indígena iniciado en 1598, que obligó al repliegue del poblamiento español al norte del río Biobío ${ }^{7}$, las alteraciones ambientales al sur del río se mantuvieron. En el verano de 1600, Fray Diego de Ocaña describe lo observado en el sector costero entre Concepción e Imperial: "Son todos estos valles fertilísimos de mantenimientos de la tierra como maíz, papas, trigo y cebada y ganado ovejuno de castilla y de la tierra y han puesto muchos parronales de uva mollar que desde el dia que los pusieron hasta el dia de hoy no se han podado y van trepando por grandísimos árboles y llevan tanto fructo que es cosa de espanto"[8].

La cultura mapuche debió asimilar rápidamente muchas de las nuevas especies biológicas para sobrevivir. Dando un paso más, las utilizó para enfrentar en mejores condiciones el dominio español. Este fenómeno antropológico, denominado "aculturación antagónica" (Zapater 1985) ${ }^{8}$, fue notorio en toda la Araucanía e influiría profundamente en las relaciones interculturales de mapuches e hispano-criollos durante todo el período colonial (Góngora 1966, Zapater 1985). Zapater (1985)

7 Como resultado de esta sublevación, que duró prácticamente una década, se perdieron todas las ciudades fundadas por los españoles al sur del Biobío: Santa Cruz de Oñez, Angol, Imperial, Villarrica, Valdivia y Osorno (Villalobos 1995).

8 El proceso de aculturación antagónica se genera cuando: "En el choque de culturas de distinto grado de desarrollo se da la posibilidad de que el grupo de menor progreso tecnológico adopte elementos culturales de la sociedad rectora. Sin embargo, asimila rasgos de vida material de la cultura ajena con el objeto de resistir mejor el dominio extraño, y poder así mantener su sistema de valores sociorreligiosos." (Zapater 1985). demuestra el proceso de aculturación antagónica mediante la adopción y adaptación que hicieron los mapuches de las armas, instrumentos de hierro, técnicas bélicas y del caballo. En este sentido, destaca la extraordinaria rapidez con que los indígenas se hicieron jinetes. Con la "araucanización del caballo", el equino pasó a jugar un rol preponderante en la cultura mapuche, especialmente en su capacidad bélica (Leiva 1981).

La adopción y asimilación de armamento y técnicas españolas por parte de los mapuches es un claro y ya probado ejemplo del fenómeno de aculturación antagónica. Sin embargo, en el presente estudio se propone que existe suficiente evidencia documental que demuestra cómo la asimilación de cereales introducidos (trigo y cebada) y la crianza del ganado exótico menor (particularmente ovinos y caprinos) también se ajustan al principio de asimilación antagónica. Este fenómeno antropológico, resultado de la necesidad de supervivencia de la etnia mapuche, se convertirá en el principal motor transformante del paisaje ecológico araucano durante la Conquista.

La descripción que hace de la guerra de Arauco el cronista y militar Alonso González de Nájera, a comienzos del s. XVII, es concluyente para reconocer la aculturación antagónica basada en la sustitución de cultivos y ganado: "Digo, pues, que del haberse sustentado nuestro campo [expedición militar] desde el principio de aquella guerra de sus naturales frutos, de los cuales el más común y de mayor nutrimento ha sido siempre su maíz, ya de poco tiempo a esta parte se han comenzado a desquitar y pagar de su mano con haber dado principio a sustentarse de nuestras propias y legítimas semillas que llevaron de España los nuestros a aquella tierra, que son nuestros trigos y cebadas de harto más sustancia que sus maíces, proveyéndose también de nuestras cabras y carneros llevados asimismo de España. Porque como el maíz que antes era el nervio principal de su sustento, es de su calidad fruto tardío, y requiere ser sembrado en tierras no solamente bajas y llanas, pero húmedas y frescas (así como vegas y cañadas), reconociendo los indios estas sus cualidades, y que eran causas que por mucho que dilatase nuestra gente cada verano sus usadas salidas a campear aguardando a que hubiese yerva en los campos del largo camino para el sustento de nuestra caballería, con todo ello no dejaba siempre de llegar a sus tierras a sazón que lo estaban en la que se había de 
coger sus maíces; y por requerir también las tierras que dije llanas, eran fáciles de hallar de los nuestros, no solo para el sustento del campo, pero para talar y destruir cuantas vegas dellos se hallaban, para necesitarlos a que dieran la paz, considerando, pues, los mismos indios cuán patente y manifiesto tenían para los nuestros su principal sustento, y no ignorando que nuestros trigos y cebadas no requerían tanto regalo como sus maíces, y que no les eran inferiores en bondad de mantenimiento, y que principalmente eran de mucho más temprana cogida para lo que era el no hallarlos por segar nuestro campo como sus maíces; estas fueron las causas que los obligó a procurar poseer suficiente parte de nuestras semillas, y así fueron procurando acaudalar las cantidades que pudieron por algunos años, así en sus particulares cautelosas paces, como en el saco [saqueo] de las ciudades que destruyeron. Las cuales semillas multiplicaron, como lo hacen maravillosamente en aquella fértil tierra"[9].

Las observaciones de González de Nájera también permiten deducir las tempranas alteraciones del paisaje araucano: "abundan de tal manera los indios de guerra de nuestros trigos y cebadas, que por sus propiedades han ido dejando casi del todo sus regalados maíces, viendo no solamente que todo terreno era apropiado para nuestras semillas, ora fuere bajo, llano, ladera o cumbre de cerro, pero que su cosecha era sin comparación mucho más temprana que la de sus maíces. De lo cual les nacen estas comodidades. La primera, que siembran sus trigos y cebadas en várias hazas divididas en sus muchos cerros no poco trabajosos y dificultosos de subir"[9].

No menos importante es la tenencia de ganado exótico entre los mapuches. El cronista señala: "fuera de lo que se ha mostrado de sus sementeras, tampoco abundaron jamás de tanta carne, como al presente poseen; pues por maravilla hay familia de indios que no posea un rebaño de ganado de nuestras cabras y carneros, que también llevaron los nuestros de España a aquella tierra, según ya dije, y especialmente de cabras por ser ganado tan a propósito para la aspereza de sus tierras, habido todo de la manera en que acaudalaron el trigo y cebada. El cual ganado multiplica maravillosamente entre ellos, por razón que no lo queman [fuerzan], como hacen los nuestros para la cosecha y granjería del cebo, según tengo referido en las excelencias de aquel reino"[9]. La importancia que tuvo la obtención de ganado exótico por parte de los araucanos queda reflejada en la cifra entregada por Encina y Castedo (1964): "entre el 23 de diciembre de 1598 y el 15 de octubre de 1600 [apogeo del alzamiento indígena] fueron arrebatadas por los indios, en las ciudades del sur, no menos de quinientas mil cabezas, entre puercos, cabros, ovejas y vacunos".

Sobre la base de lo anterior, se puede deducir que la sociedad mapuche araucana, y por ende su hábitat, experimentaron progresivos y sustanciales cambios desde los inicios de la Conquista.

Efectos ambientales del poblamiento hispano-criollo. Una de las primeras secuelas de la conquista española fue la significativa disminución de la población araucana. El aumento de la mortalidad se debió al contagio epidémico de nuevas enfermedades, a la guerra y al trabajo forzado (Encina y Castedo 1964). Como lo observa el mordaz cronista Mariño de Lobera, al referirse a la recién fundada Concepción, este fenómeno afectó principalmente a los asentamientos mapuches aledaños a los enclaves españoles: "Tiene esta ciudad una hermoza comarca de quince leguas [...]: habia en esta comarca ... arriba de cien mil indios cuando se pobló, y al tiempo en que esto se escribe, [ $\mathrm{ca}$. 1594] no hai diez mil, por los buenos tratamientos que los españoles les hacen, y las continuas guerras de la comarca"[10].

Junto con aumentar la mortalidad mapuche, la actividad bélica también influyó sobre la tipología (mayoritariamente soldados) y distribución geográfica del poblamiento español fronterizo. De acuerdo a los antecedentes entregados por el historiador colonial Pedro de Córdoba y Figueroa, el poblamiento hispano del sector septentrional de la Araucanía se materializó en la última década del s. XVI, teniendo su origen en un pequeño asentamiento militar (fortín), localizado en la ribera sur del río Biobío [11]. Esta instalación sería posteriormente abandonada al iniciarse la sublevación mapuche de 1598 .

La exitosa sublevación indígena redujo los asentamientos hispanos de la Araucanía a sólo algunos enclaves militares ubicados principalmente al norte del Biobío. Sin embargo, el interés colonizador junto a la resistencia de abandonar la totalidad del territorio ya conquistado motivó a Alonso de Ribera, gobernador de Chile durante 1601-1605 y 1612-1615, a establecer una línea fortificada en el curso inferior del río (Guarda 1990). La fundación de fuertes fronterizos significó una importan- 
te tala de árboles nativos para su construcción, generando una primera alteración ambiental: "Hice los fuertes que hice de palizadas pequeños, que se podían guardar con cincuenta o sesenta hombres, muy defendibles y ofensibles... a la moderna, de tal manera que todas las veces que el enemigo vino a ellos fue muy bien descalabrado y son muy diferentes fuertes de los que en Chile se han usado hasta que yo vine a él"[12]. La información de Ribera es corroborada por el cronista González de Nájera, quien entonces servía como oficial en la frontera. "Son pues los fuertes que dije en cuanto a su materia [...], de palizada, quiero decir, de unos palos los más derechos que se hallan a mano del sitio donde se fundan con la rustiquez que se cortan, y de grosor indiferente, que los que más lo son, serán poco más que el timón o pértigo de un carro, y de altura de catorce o quince piés, cual más y cual menos, los cuales plantados hasta una rodilla o tres palmos, bien firmes, ajuntados unos con otros, van de tal manera haciendo hilera por lo diseñado componiendo y cerrando la circunferencia o espacio del trazado sitio"[13].

La tala del bosque no sólo se limitaba al momento de la construcción del fuerte. En la práctica se realizaba permanentemente, debido a que la guarnición requería del abastecimiento cotidiano de leña "para la guardia y otros ministerios"[14], y de madera para reparar los daños causados por los ataques mapuches: "el fuerte estaba tan sin figura, según lo habían desbaratado, que había harto que reparar en él, a causa de los muchos palos que tenía cortados y arrancados, y los grandes hoyos que por debajo de la palizada habían hecho"[15].

No menos importantes eran los efectos del clima y catástrofes naturales en el rápido deterioro de las estructuras de madera. Un informe de las condiciones del fuerte de San Pedro indica que: "se halló en el mismo estado a que la reduxo el temblor del año pasado de 1751 en el que se vinieron a tierra enteramente los quarteles, almacenes, iglesia, casa del cura y demás oficinas sin haberse reedificado desde entonces acá [...] el terreno en que está fundado este fuerte que es de arena muerta al margen del caudaloso río de Biobío, cuia avenida le han rovado en el curso de los años una quadra, o mas de tierra que tenía de distancia a dicho río: y mediando que desta proporción en breve se vería destruida qualquiera nueva obra que se volviese a reedificar en él, por la fragilidad sería expuesta a terremotos y a las aguas, con duplicados gastos del real tesoro"[16].
Parte de un informe posterior indica: "Plaza de San Pedro: La mayor parte de la estacada es preciso renovarla por estar podrida"[17]. Del mismo modo, existen planos del s. XVIII (Guarda 1990), que muestran los cambios de trazado arquitectónico del mismo fuerte, demostrándose las sucesivas reparaciones o reconstrucciones que fueron necesarias con el tiempo.

Sobre la base de los antecedentes, es posible deducir que en los alrededores de los fuertes se realizó una sostenida tala arbórea; sin embargo, es difícil cuantificar el real impacto ambiental generado y los efectos ecológicos sobre el bosque.

Paralelamente y de acuerdo a la estrategia militar de Ribera, el establecimiento de fuertes suponía incursiones punitivas (campeadas) que buscaban el sometimiento de la población indígena local: "comencé a tomar puestos, fortificándome en los más cómodos para abrigar la tierra de V.M. y ofender la del enemigo, en la cual entré al tiempo que convino, quitándole las comidas, quemándoles casas y tomándoles hijos y mujeres, teniéndolos en perpetua inquietud, sin dejarlos reposar un punto"[18]. Necesariamente, este método bélico debió generar modificaciones ambientales (e.g. incendios descontrolados, aumento de la mortalidad y migración indígena) en las áreas jurisdiccionales de los fuertes. Así, el propio González de Nájera reconoce el efecto de los fuertes sobre la población indígena: "[no eran] de otro provecho más de para solo hacer que despueblen los indios de guerra espacio de dos leguas poco más o menos a la redonda de cada fuerte, en la comarca que se funda, de donde se ausentan, porque no los cojan los nuestros en sus salidas tan cerca, descuidados en sus alojamientos" [19].

Al declinar la guerra, a fines del s. XVII, los fuertes originaron núcleos poblacionales hispanocriollos que prosperaron gracias al amparo militar (Cunill 1971). Se trataba de familias de pioneros asociadas a las actividades agropecuarias de los mismos militares, quienes las desarrollaron para su autosustento y aumentar sus ingresos económicos (Cunill 1971). De esta forma, dichos núcleos se convirtieron en polos radiales de introducción de la agroganadería hispano-mediterránea en la Araucanía y, por ende, en los primeros polos formales de intervención ambiental.

Probablemente el auge triguero generado a fines del s. XVII también contribuyó al avance agrícola en la Araucanía. Debido a la demanda peruana, entre los años 1692 y 1695 se duplica la siem- 
bra de trigo en las tierras al norte del Biobío, generándose el desplazamiento de otros cultivos y la intensificación en el uso del suelo (Cunill 1971). La tesis del temprano avance agrícola en la Araucanía se corrobora al reconocer, en la documentación de época, que hacia 1698 se instala un establecimiento agropecuario formal (estancia o hacienda) inmediatamente al sur del Biobío: "a legua y media de este paraje [fuerte de San Pedro], estan las lagunillas en que estan unos indios de la encomienda de Don Juan de Espinoza ${ }^{9}$ vecino de la Concepción pues, es el único que posee encomienda pasado el Viobio"[20].

Durante el s. XVIII, período en que alternaron largos períodos de paz con ocasionales rebeliones indígenas, aumentó el dominio efectivo de los fuertes, estimulándose el establecimiento de nuevas haciendas al sur del Biobío. En el gobierno de Manuel de Amat y Junient (1755-1761), la jurisdicción del fuerte San Pedro alcanzaba hasta la Punta del Coronel que "en lo interior está poblada de Indios, cuyas Rancherías estan a corta distancia, como son los del Coronel, y Escuadron que estan sujetos al Comandante de la Plaza de San Pedro, con los de las Lagunillas [...]. Todos estos indios son pocos, y tienen sus respectivos Caciques: mantienen de Labranzas de tierras, y Mariscos, de lo que entablan Comercio con los Españoles"[21]. Continúa más adelante: "Palco es Hacienda a la orilla del Biobío a la parte del Sur y tiene Ranchería de Indios al cuidado del Comandante de la Plaza de Sn Pedro. Es parage de mucho Monte [cerros boscosos] y buenas Maderas" $[21]^{10}$.

La coexistencia de establecimientos agropecuarios hispano-criollos y población mapuche supone el empleo de mano de obra indígena en faenas productivas similares a las realizadas en las haciendas al norte del Biobío (sensu Cunill 1971). En consecuencia, es probable un importante tras-

9 Esta encomienda de indios fue otorgada al padre de Juan de Espinoza (Pedro de Espinoza ), por el Gobernador Tomás Marín de Poveda el 29 de enero de 1698, según consta en Real Cédula sobre confirmaciones de encomiendas de yanaconas fechada a 20 de noviembre de 1702 (Jara y Pinto 1982 ).

10 Es posible deducir que, desde inicios del s. XVIII, las localidades de Punta del Coronel (litoral marino) y Palco (ribera del Biobío) constituían el límite sur del dominio del fuerte de San Pedro. Desde allí se iniciaban las respectivas jurisdicciones de los fuertes de San Miguel Arcángel de Colcura y Santa Juana de Guadalcázar. paso cultural de las nuevas técnicas de labranza, aprendizaje del uso de herramientas como el arado y las "rejas" o rastras, y el manejo ganadero. Antecedentes entregados en 1782 por el botánico Hipólito Ruiz comprueban la expansión del poblamiento y crianza de ganado al sur del Biobío: "Pasado el Rio [...] en toda esta costa que es realenga, hay varios potreros de caballos del Rey custodiados por muchas familias de guazos que viven repartidos en rancherias en aquella espaciosa y amena campiña, en la cual siembran y cosechan diferentes frutos y semillas para su manutención con la precisa obligación de ser todos Milicianos y de estar prontos en caso necesario de salir a campaña contra los Indios"[22].

Hacia 1803, el ingeniero militar Juan de Ojeda entrega información que confirma el sostenido crecimiento de las actividades agrícolas y ganaderas desarrolladas en el sector septentrional de la Araucanía: "tierras de llanos i vegas fertilísimas al pasto y labor, en donde habitan muchos españoles hacendados i bien acomodados. La punta del Coronel es un gran potrero que de tiempo inmemorial han gozado i poseido los jefes de las armas de frontera. Las demas tierras del oriente son de montaña que se deslindan con las de Santa Juana, mui propias para ganado vacuno, del que se hallan ocupadas. Se fabrica porción de mantequilla, se cocecha mucha cebada, papas i demas legumbres trimecinas con abundancia; la pesca se hace con aprovechamiento, i todo se comercia en Concepción"[23].

Posteriormente, con la consolidación de la República de Chile, se procedió a colonizar formalmente toda la Araucanía, incorporando este territorio a la explotación irracional de los recursos naturales para satisfacer la demanda nacional e incluso internacional de materias primas. De este modo, se generó una segunda etapa de intervención ambiental, de proporciones muy superiores a la reconocida en la presente investigación, evolucionando a las actuales condiciones ambientales, que nos muestran un paisaje altamente deteriorado e intervenido. El reconocimiento de una temprana intervención ambiental obliga a que los futuros estudios medioambientales modifiquen sus enfoques, en el sentido de dejar de considerar que las actuales condiciones del paisaje ecológico araucano responden sólo a los sucesos acontecidos durante el último siglo. 


\section{CONCLUSION}

A través de dos procesos históricos, la guerra de Arauco y el poblamiento hispano-criollo, se han reconocido las distintas fases del proceso de intervención ambiental temprana de los sectores central y septentrional de la Araucanía. De este modo, se demuestra, contrariamente a lo supuesto tradicionalmente, que el paisaje ecológico araucano fue perdiendo su pristinidad desde el mismo momento que llegaron los conquistadores españoles y que la aparente independencia política que mantuvo no fue barrera suficiente para impedir el avance de la agroganadería hispano-mediterránea y sus secuelas ambientales:

- Extinciones locales de especies nativas: llama (Lama lama), mango (Bromus mango) y teca.

- Introducción de especies biológicas de origen exótico; animales (caballares, bovinos, ovinos y caprinos, entre otros) y vegetales (trigo, cebada, vid y otros frutales, además de diferentes tipos de hortalizas).

- Sustitución de cultivos mapuches y pérdida de variedades tradicionalmente cultivadas como la quinoa (Chenopodium quinoa) y madi (Madia sativa), entre otras.

- Reemplazo de un uso armónico de los recursos naturales por un uso predatorio, extractivo y mercantil.

- Cambios en el uso del suelo. Reemplazo del uso extensivo por el uso intensivo (monocultivos agrícolas y ganadería).

- Modificación del acervo cultural de la etnia mapuche.

- Aumento de la mortalidad y migración de la población araucana.

\section{BIBLIOGRAFIA}

AMBERGA, J. 1917. "Agricultura Araucana”, Revista Chilena de Historia y Geografía 25: 54-80.

BARROS ARANA, D. 1884-1904. Historia jeneral de Chile. Editorial R. Jover, Santiago, Chile (16 tomos).

BENGOA, J. 1991. Historia del Pueblo Mapuche (siglos XIX y XX). Ediciones Sur, Santiago, Chile. $426 \mathrm{pp}$.

BULLOCK, D. 1958. "La Agricultura de los Mapuches en tiempos Pre-Hispánicos", Boletín de la Sociedad de Biología de Concepción (apartado): 141-154.

CUNILL, P. 1970. Factores en la destrucción del paisaje chileno: recolección, caza y tala coloniales. Informaciones Geográficas (número especial): 235-264.
CUNILL, P. 1971. "Chile meridional criollo: su geografía humana en 1700", Cuadernos Geográficos del Sur (número único): 21-75.

CUNILL, P. 1998. Apuntes curso de postgrado "Geohistoria Ambiental Latinoamericana”. Centro EULA-Chile, Universidad de Concepción, Chile. 120 pp.

CHONCHOL, J. 1994. Sistemas agrarios en América Latina, de la etapa prehispánica a la modernización conservadora. Fondo de Cultura Económica S.A., Santiago, Chile. 74 pp.

ENCINA, F. 1947. Historia de Chile, desde la prehistoria hasta 1891. Editorial Nascimento, Santiago, Chile (20 tomos).

ENCINA, F. L. CASTEDO 1964. Resumen de la Historia de Chile. Empresa Editora Zig-Zag, Santiago de Chile, tomo I. $220 \mathrm{pp}$.

GONGORA, M. 1966. Vagabundaje y sociedad fronteriza en Chile (siglos XVII a XIX). Editorial Facultad de Ciencias Económicas de la Universidad de Chile, Santiago. 85 pp.

GONZALEZ, S, R. RODRIGUEZ, M. BAEZA. 1991. Arboles del Bío-Bío. Ediciones Universidad de Concepción, Santiago, Chile. 96 pp.

GUARDA, G. 1990. Flandes Indiano. Las fortificaciones del Reino de Chile 1541-1826. Ediciones de la Universidad Católica de Chile, Santiago. 52 pp.

GUEVARA, T. 1925. Chile prehispano. Bacells \& Co., Santiago de Chile. $246 \mathrm{pp}$.

JARA, A., S. PINTO. 1982. Fuentes para la historia del trabajo en el Reino de Chile. Legislación, 1546-1810. Editorial Andrés Bello, Santiago, tomo II. 76 pp.

KRUMM, G. 1971. "División territorial de la Araucanía", Revista Chilena de Historia y Geografía, 139: 87-104.

KRUMM, G. 1972. "División territorial de la Araucanía", Revista Chilena de Historia y Geografía 140: 242-246.

LATCHAM, R. 1922. Los animales domésticos de la América Precolombina. Publicaciones del Museo de Etnología y Antropología, Santiago de Chile (1922):129-142.

LATCHAM, R. 1936. La agricultura precolombina en Chile y los países vecinos. Ediciones de la Universidad de Chile, Santiago. 322 pp.

LEIVA, A. 1981. La araucanización del caballo en los siglos XVI y XVII. Anales de la Universidad de la Frontera, Temuco: 181-203.

MASUDA, S. 1998. Algas y algueros en Chile. En: Recursos naturales andinos. (Editores). Universidad de Tokio. $25 \mathrm{pp}$. MEFFE, G., R. CARROLL. 1994. Principles of conservation biology. Sinauer Associates Inc., Sunderland, Massachusetts, USA. $190 \mathrm{pp}$

PACHECO, A. 1991. "Una economía de conquista, Concepción siglo XVI", Revista de Historia, Universidad de Concepción 1: 25-44.

RODRIGUEZ, G., R. RODRIGUEZ, H.L. BARRALES. 1995. Plantas ornamentales chilenas. Editora Aníbal Pinto S.A., Concepción, Chile. 45 pp.

SAN MARTIN, J., C. DONOSO. 1997. Estructura florística e impacto antrópico en el bosque maulino de Chile. En: Armesto, J. et al. (eds.). Ecología de los bosques nativos de Chile. Editorial Universitaria, Santiago de Chile. 67 pp.

STEHBERG, R. 1980. Diccionario de Sitios Arqueológicos de Araucanía. Publicación N ${ }^{\circ} 31$, Museo Nacional de Historia Natural, Santiago, Chile. 209 pp.

VILLALOBOS, S. 1983. Historia del pueblo chileno. Editora Zig-Zag, Santiago de Chile (tomo I), $110 \mathrm{pp}$

VILLALOBOS, S. 1995. Vida fronteriza en la Araucanía, el mito de la guerra de Arauco. Editorial Andrés Bello, Santiago de Chile. 130 pp.

ZAPATER, H. 1985. Parlamentos de paz en la Guerra de Arauco. En: Villalobos, S., J. Pinto (Eds.), Araucanía, temas de historia fronteriza. Ediciones Universidad de la Frontera, Temuco, Chile, pp. 47-82. 
[1] Vivar, Jerónimo de. "Crónica y relación copiosa y verdadera de los Reinos de Chile (1558)". Edición de Leopoldo Sáez-Godoy, Biblioteca IberoAmericana, Colloquium Verlag, Berlín, 1970, pp. 181-182.

[2] Valdivia, Pedro de. "Cartas que tratan del descubrimiento y conquista de la Nueva Extremadura". Edición facsímil realizada en conmemoración del Quinto Centenario del Encuentro de Dos Mundos, Editorial Andrés Bello, España, 1991, p. 131.

[3] Vivar, Jerónimo de. "Crónica y relación copiosa y verdadera de los Reinos de Chile (1558)". Edición de Leopoldo Sáez-Godoy, Biblioteca IberoAmericana, Colloquium Verlag, Berlín, 1970, pp. 175.

[4] Valdivia, Pedro de. "Cartas que tratan del descubrimiento y conquista de la Nueva Extremadura". Edición facsímil realizada en conmemoración del Quinto Centenario del Encuentro de Dos Mundos, Editorial Andrés Bello, España, 1991, p. 166.

[5] Valdivia, Pedro de. "Cartas que tratan del descubrimiento y conquista de la Nueva Extremadura". Edición facsímil realizada en conmemoración del Quinto Centenario del Encuentro de Dos Mundos, Editorial Andrés Bello, España, 1991, p. 132.

[6] Vivar, Jerónimo de. "Crónica y relación copiosa y verdadera de los Reinos de Chile (1558)". Edición de Leopoldo Sáez-Godoy, Biblioteca IberoAmericana, Colloquium Verlag, Berlín, 1970, pp. 186.

[7] Mariño de Lobera, Pedro. "Crónica del Reino de Chile". En: Colección de Historiadores de Chile, Imprenta del Ferrocarril, Santiago, 1865, tomo VI, p. 123.

[8] Ocaña, Diego de. "Viaje a Chile. Relación del viaje a Chile, año de 1600 , contenida en la crónica de viaje intitulada 'A través de la América del Sur' ". Editorial Universitaria, Santiago de Chile, 1995, pp. 37-38.

[9] González de Nájera, Alonso. "Desengaño y reparo de la guerra del Reino de Chile". Editorial Andrés Bello, Santiago de Chile, 1971, pp. 175-178.

[10] Mariño de Lobera, Pedro. "Crónica del Reino de Chile". En: Colección de Historiadores de Chile, Imprenta del Ferrocarril, Santiago, 1865, tomo VI, p. 118.

[11] Córdoba y Figueroa, Pedro de. "Historia de Chile (1492-1717)". En: Colección de Historiadores de Chile. Imprenta del Ferrocarril, Santiago, 1862, tomo II, p. 186.

[12] Carta de Alonso de Ribera a su Majestad. Febrero 22 de 1604. En: Medina, José T. "Colección de Documentos Inéditos para la Historia de Chile".
Fondo Histórico y Bibliográfico J. T. Medina, Santiago de Chile, 1982, Segunda Serie, tomo III, pp. 538-548; p. 540.

[13] González de Nájera, Alonso. "Desengaño y reparo de la guerra del Reino de Chile". Editorial Andrés Bello, Santiago de Chile, 1971, pp. 181.

[14] Carta de Alonso de Ribera a su Majestad. Colina, 18 de septiembre de 1605. En: Medina, José T. Op. cit., pp. 559-574; p. 564.

[15] González de Nájera, Alonso. "Desengaño y reparo de la guerra del Reino de Chile". Editorial Andrés Bello, Santiago de Chile, 1971, pp. 187.

[16] Informe del Gobernador Manuel de Amat y Junient, fechado en el fuerte de San Pedro a quince días de diciembre de 1758. Archivo Nacional de Chile, Santiago, Archivo Contaduría Mayor, $1^{a}$ Serie, Vol. 1052, fjs. 50-51.

[17] Relación que manifiesta los reparos que necesitan como más urgentes todas las Plazas de esta Frontera de los indios, con expresión del importe que se considera tendrán, según cálculo prudencial. Leandro de Badarán, Concepción 7 de febrero de 1775. Archivo Nacional de Chile, Santiago, Fondo Capitanía General, Vol. 861, fjs. 99-100.

[18] Carta de Alonso de Ribera a su Majestad. Colina, 18 de septiembre de 1605. En: Medina, José T. Op. cit., pp. 559-574; p. 561-562.

[19] González de Nájera, Alonso. "Desengaño y reparo de la guerra del Reino de Chile". Editorial Andrés Bello, Santiago de Chile, 1971, pp. 193.

[20] Carta de Don José González de la Rivera a S.M. el Rey, fecha en Nuestra Señora del Carmen de Repocura a 20 de Enero de 1699. Biblioteca Nacional de Chile, Santiago, Sala J.T. Medina, Manuscritos, tomo 170, fjs. 141-158; fjs. 146.

[21] Amat, Manuel de. "Historia geográfica é hidrográfica con derrotero general correlativo al Plan del Reino de Chile". En: Revista Chilena de Historia y Geografía, Nros. 53, 55, 56, 57, 58, 59, 60, 61 y 62, Santiago de Chile, 1924-1928; № 57, p. 394 y 401.

[22] Ruiz, Hipólito. "Relación del viaje hecho a los reynos del Perú y Chile por los botánicos y dibuxantes enviados para aquella expedición, extractado de los diarios por el orden que llevó en estos su autor". Real Academia de Ciencias Exactas, Físicas y Naturales, Estudio Tipográfico Huelves y Cía, Madrid, 1931, pp. 165-166.

[23] Ojeda, Juan de. "Informe descriptivo de la frontera de la Concepción de Chile". En: Anrique, Nicolás (Compilador). Biblioteca Jeográfica Hidrográfica de Chile, Imprenta Elzeviriana, Santiago de Chile, 1898, pp. 223-292; p. 267. 